\title{
IKK inhibitor suppresses epithelial-mesenchymal transition and induces cell death in prostate cancer
}

\author{
HAO PING ${ }^{*}$, FEIYA YANG ${ }^{*}$, MINGSHUAI WANG, YINONG NIU and NIANZENG XING \\ Department of Urology, Beijing Chaoyang Hospital, Capital Medical University, Beijing 100020, P.R. China
}

Received February 22, 2016; Accepted May 31, 2016

DOI: $10.3892 /$ or.2016.4915

\begin{abstract}
I $\kappa \mathrm{B}$ kinase (IKK)/nuclear factor $\kappa \mathrm{B}(\mathrm{NF}-\kappa \mathrm{B})$ pathway activation is a key event in the acquisition of invasive and metastatic capacities in prostate cancer. A potent smallmolecule compound, BMS-345541, was identified as a highly selective IKK $\alpha$ and IKK $\beta$ inhibitor to inhibit kinase activity. This study explored the effect of IKK inhibitor on epithelialmesenchymal transition (EMT), apoptosis and metastasis in prostate cancer. Here, we demonstrate the role of IKK inhibitor reducing proliferation and inducing apoptosis in PC-3 cells. Furthermore, BMS345541 inhibited I $\kappa \mathrm{B} \alpha$ phosphorylation and nuclear level of $\mathrm{NF}-\kappa \mathrm{B} / \mathrm{p} 65$ in $\mathrm{PC}-3$ cells. We also observed downregulation of the N-cadherin, Snail, Slug and Twist protein in a dose-dependent manner. BMS-345541 induced upregulation of the epithelial marker E-cadherin and phosphorylated NDRG1 at protein level. Moreover, BMS-345541 reduced invasion and metastasis of PC-3 cells in vitro. In conclusion, IKK has a key role in both EMT and apoptosis of prostate cancer. IKK inhibitor can reverse EMT and induce cell death in PCa cells. IKK was identified as a potential target structure for future therapeutic intervention in $\mathrm{PCa}$.
\end{abstract}

\section{Introduction}

Prostate cancer ( $\mathrm{PCa}$ ) is one of the most common malignancies and one of the leading causes of cancer deaths in men in the Western world. There are many therapeutic options against localized prostate cancer including prostatectomy and radiation therapy (1). However, in advanced cancer, most tumors ultimately relapse after a period of initial response to therapy and progress to metastatic cancer $(2,3)$. It is still a clinical

Correspondence to: Professor Nianzeng Xing, Department of Urology, Beijing Chaoyang Hospital, Capital Medical University, 8 Gongren Tiyuchang Nanlu, Beijing 100020, P.R. China

E-mail: xingnianzeng@126.com

${ }^{*}$ Contributed equally

Key words: IкB kinase, IKK inhibitor, epithelial-mesenchymal transition, BMS-345541, apoptosis, prostate cancer challenge to deal with advanced prostate cancer in patients. Unfortunately, many aspects remain unknown of the cellular and molecular mechanisms for metastatic disease (4). As is known, epithelial-mesenchymal transition (EMT) plays essential roles in development, invasion and migration of prostate cancer. EMT is characterized by loss of homotypic adhesion and cell polarity (5). The most familiar change that occurs during EMT is the downregulation of surface E-cadherin expression and increased expression of $\mathrm{N}$-cadherin. Many signaling pathways, including TGF- $\beta$, Wnt, notch, PI3K/AKT, and hedgehog, have been intricately connected to the onset of EMT (6). A number of studies have reported that EMT-inducing transcription factors, such as Snail, Slug, Twist, and Zeb, are directly or indirectly involved in cancer cell metastasis through different signaling cascades and pathways (7).

Nuclear factor $\kappa \mathrm{B}(\mathrm{NF}-\kappa \mathrm{B})$ signaling has been previously identified as an important pathway in the regulation of EMT in tumor progression (8). The $\mathrm{NF}-\kappa \mathrm{B}$ family is composed of five proteins, including Rel-A/p65, Rel-B, C-Rel, p52, and p50. In unstimulated cells, uninduced $\mathrm{NF}-\kappa \mathrm{B}$ dimers are restrained in the cytoplasm by complex formation with a member of the I $\mathrm{B}$ family (9). On stimulation, I $\mathrm{KB}$ proteins are phosphorylated by the multisubunit I $\mathrm{B}$ kinase (IKK) complex, subsequently ubiquitinated and degraded through the proteasomal pathway. Then, the liberated $\mathrm{NF}-\kappa \mathrm{B}$ heterodimer rapidly translocates into the nucleus, where it binds to the $\kappa \mathrm{B}$ site and induces transcription of a wide variety of target genes involved in cancer development and progression (10). The IKK complex consists of IKK $\alpha /$ IKK 1 , IKK $\beta /$ IKK 2 , and IKK $\gamma /$ NEMO. Recently, two protein kinases called IKK $/$ IKKi and TBK1 (TANK-banding kinase) were identified that exhibit structural similarity to $\operatorname{IKK} \alpha$ and IKK $\beta$ (11). However, it remains unclear what is the regulation relationship between upstream $\mathrm{NF}-\kappa \mathrm{B}$ activator IKK family members and EMT in prostate cancer.

Because IKK is a key molecular complex specifically regulating $\mathrm{I} \kappa \mathrm{B}$ proteins and subsequently targeting $\mathrm{NF}-\kappa \mathrm{B}$, we speculated that IKK would be a potential therapeutic target for prostate cancer. A potent small-molecule compound, BMS-345541, was identified as a highly selective IKK $\alpha$ and IKK $\beta$ inhibitor to inhibit kinase activity (12). To determine whether IKK inhibitor manipulates the process of EMT and cell death, we delivered the BMS-345541 drug to human prostate cancer PC-3 cell in vitro. Here we investigated the detailed effect of IKK inhibitor on EMT, apoptosis, and metastasis in prostate cancer cells. 


\section{Materials and methods}

Biological reagent. BMS-345541 (4(2'-aminoethyl) amino-1, 8-dimethylimidazo(1,2- $\alpha)$ quinoxaline) were obtained from Calbiochem (San Diego, CA, USA). BMS-345541 was dissolved in DMSO to produce a $50-\mathrm{mmol} / 1$ stock solution for experiments. All phosphospecific or total antibodies used in this study were purchased from Cell Signaling Tech (Denver, MA, USA) and Santa Cruz Biotech (Santa Cruz, CA, USA).

Cell culture. PC-3 and LNCaP cells were obtained directly from the American Type Culture Collection (Manassas, VA, USA). All cell lines were grown in RPMI-1640 medium (Gibco) both supplemented 10\% heat-inactivated FBS (fetal bovine serum), $100 \mathrm{IU} / \mathrm{ml}$ penicillin, $100 \mu \mathrm{g} / \mathrm{ml}$ streptomycin, $0.1 \mathrm{mM}$ non-essential amino acids, $0.2 \mathrm{mM}$ glutamine, and $1 \mathrm{mM}$ pyruvate and incubated at $37^{\circ} \mathrm{C}$ in a $5 \% \mathrm{CO}_{2}$ incubator. Cells were treated with BMS-345541 in the following experiments. Cell treated with DMSO were used as controls. Each experiment was repeated three times.

Cell viability assay by MTT. The cells were seeded in a 96-well culture plate and cultured overnight. The MTT assay was used to determine cell viability. BMS-345541 was added to the cells in different time and concentration. The MTT regent $(5 \mathrm{mg} / \mathrm{ml})$ was added and the cells then incubated for a further $4 \mathrm{~h}$. The reduced MTT crystals were dissolved in DMSO and the absorbance was detected on BioTek ELISA reader (Winooski, VT, USA) at $570 \mathrm{~nm}$ wavelength.

Cell invasion assay. The cell invasion assay was performed using Boyden chambers with $8 \mu \mathrm{m}$ porosity polyvinylpyrrolidone-free polycarbonate filters coated with $50 \mu \mathrm{g} / \mathrm{ml}$ Matrigel solution. The cells in 24-well plates at a concentration of $5 \times 10^{4} /$ well were cultured for $24 \mathrm{~h}$ with DMSO and BMS-345541, respectively. Normal culture medium was added to the bottom chamber to induce the cancer cell lines. Pretreated cell were seeded in the top chamber. The Matrigel invasion chamber was incubated for $24 \mathrm{~h}$ in a humidified culture incubator, and after $24 \mathrm{~h}$, the non-invasive cells were removed from the upper surface of the separating membrane using a cotton swab. The invading cells were then fixed in $100 \%$ methanol and stained with $0.1 \%$ crystal violet solution. They were counted using a microscope (magnification, $\mathrm{x} 200$ ).

Wound healing assay. Cells were cultured to reach 100\% confluency and were pretreated with DMSO or IKK inhibitor (BMS-345541) for $12 \mathrm{~h}$ in culture medium supplemented with $10 \%$ FBS. A scratch wound was created on the cell surface using a micropipette tip. The wound area was photographed by bright-field microscopy every $8 \mathrm{~h}$ for $48 \mathrm{~h}$. The width of the wound was measured and the wound closure rate was calculated.

Western blotting. For isolation of total protein, control and treated cells were washed in ice cold PBS. Briefly, treated cells were lysed in modified lysis buffer containing $50 \mathrm{mM}$ Tris- $\mathrm{HCl}$ (pH 7.4), $150 \mathrm{mM} \mathrm{NaCl}, 1 \%$ NP-40, $0.1 \%$ SDS, $1 \mathrm{mM}$ EDTA, 1 mM EGTA, $20 \mathrm{mM} \mathrm{NaF}, 1 \%$ sodium deoxycholate and protease inhibitor cocktail (Roche, Mannheim, Germany).
After lysis, the lysates were centrifuged for $10 \mathrm{~min}$ at $13,000 \mathrm{~g}$ at $4^{\circ} \mathrm{C}$. Total protein samples $(25-50 \mu \mathrm{g})$ were transferred onto PVDF membrane after electrophoretic separation in $12 \%$ SDS polyacrylamide gel. After blocked with $5 \%$ non-fat milk in Tris-buffered saline for $1 \mathrm{~h}$ at room temperature, the membranes were incubated overnight with the primary antibody at $4^{\circ} \mathrm{C}$ and washed three times in PBS containing $0.1 \%$ Tween-20, then incubated with the horseradish peroxidase conjugated secondary antibodies at room temperature for $1 \mathrm{~h}$. The membranes were washed three times in PBS, and then developed with a horseradish peroxidase chemiluminescence detection reagent and exposed to X-ray film.

TUNEL apoptosis assay. A quantitative evaluation method was applied by using terminal deoxynucleotidyl transferasemediated deoxyuridine triphosphate (TdT) nick-end labelling (TUNEL) kit to examine apoptotic cells. Briefly, coverslips with adherent cells treated with BMS-345541 $(5 \mu \mathrm{mol} / \mathrm{l})$ for $72 \mathrm{~h}$ were fixed in $4 \%$ paraformaldehyde at room temperature for $30 \mathrm{~min}$. Then they were rinsed in distilled water and incubated in PBS containing $0.2 \%$ Triton X-100. DNA fragments were labeled with TUNEL-enzyme (Boehringer Mannheim). The kit was used according to the manufacturer's instructions, with the addition of incubation in $\mathrm{TdT}$ reaction buffer for $10 \mathrm{~min}$ before TUNEL reaction. The coverslips were then incubated in TdT reaction mixture for $60 \mathrm{~min}$ at $37^{\circ} \mathrm{C}$ in humidified chamber, rinsed in stop wash buffer for $10 \mathrm{~min}$ and washed by PBS for 3 times. The reaction was detected by incubating coverslips with streptavidin-HRP in PBS for $30 \mathrm{~min}$ at room temperature. Then washed by PBS 3 times, and the sections were incubated with DAB solution for $10 \mathrm{~min}$.

Assessment of the apoptotic index. Positive signal was defined as the presence of a dark brown staining on the nuclei of the neoplastic cells or on apoptotic bodies as morphologically defined. Cells were defined as apoptotic if the whole nuclear area of cells labeled positively. Apoptotic bodies were defined as small, positively labeled, globular bodies in the cytoplasm of the tumor cells that could be found either singly or in groups. The apoptotic index was determined by the percentage of apoptotic cells divided by the number of tumor cells in $x 400$ magnification. A total of $\geq 1,000$ neoplastic nuclei were counted based on 10 randomly chosen fields at x400 magnification. Apoptotic cells were identified by TUNEL in conjunction with characteristic morphological changes, such as cell shrinkage, membrane blebbing, and chromatin condensation.

Statistical analysis. Data are expressed as mean \pm standard deviation (SD) from three independent experiments. All statistical analyses were performed using the SPSS 19.0 for Windows software system. Data with two groups were analyzed by Student's t-tests, and data with multiple groups were analyzed by one-way ANOVA. A significant difference was considered when the P-value from a two-tailed test was $<0.05$.

\section{Results}

BMS-345541 inhibits the growth of prostate cancer cells. Since inappropriate regulation of IKK/NF- $\kappa \mathrm{B}$ correlates with prostate caner progression, IKK inhibitor might be a 

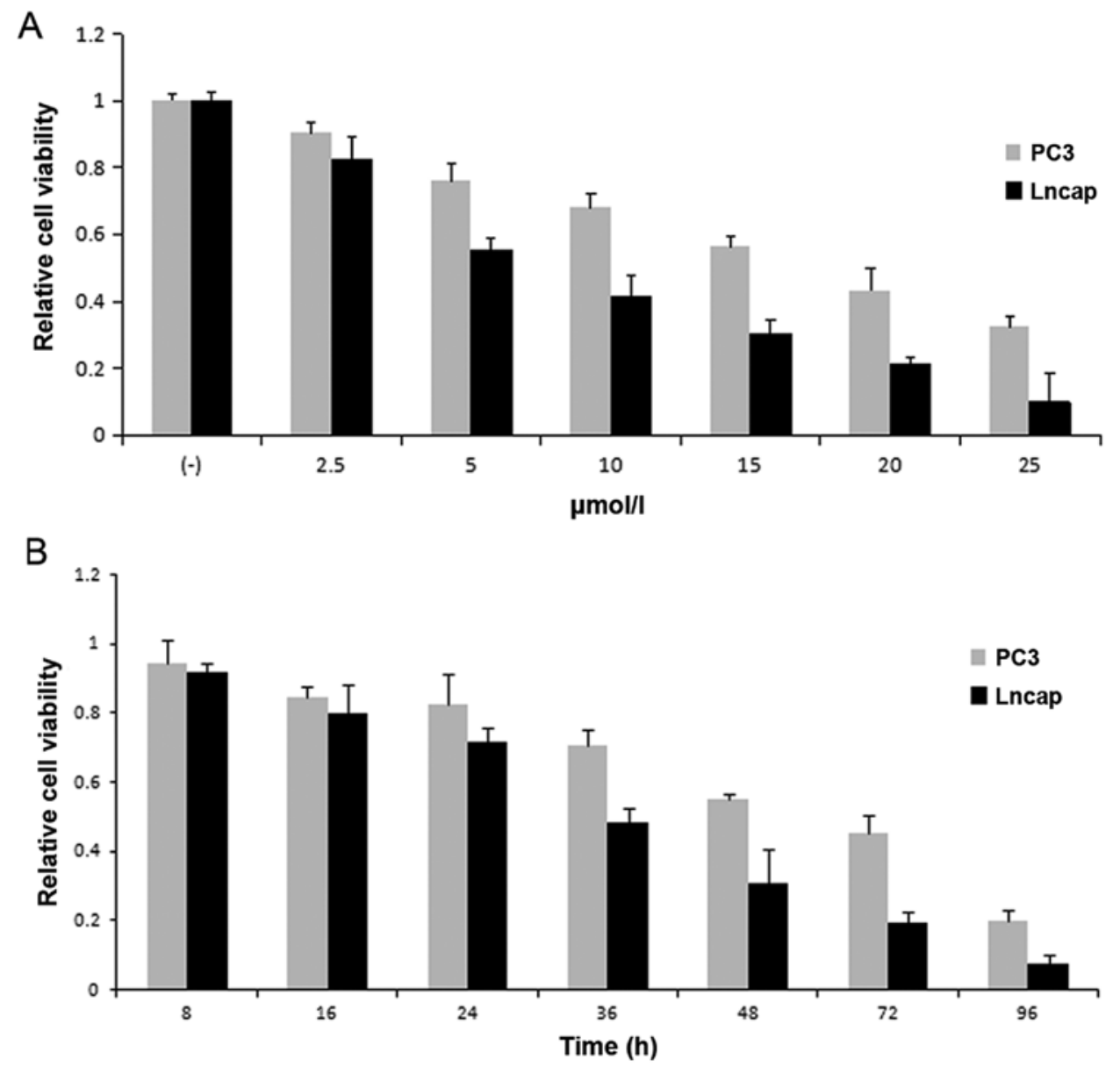

Figure 1. Effect of BMS-345541 on the growth of prostate cancer cells. Cell viability was assessed by MTT assay. (A) PC-3 and LNCaP cells were treated with various concentrations of BMS-345541 (0-25 $\mu \mathrm{mol} / \mathrm{l})$. From the results of MTT assay, the inhibition rate of prostate cancer cells treated with varying doses showed a dose-dependent increase. (B) Cells were treated with BMS-345541 at different times (8-96 h). BMS-345541 reduced cell viability in a time-dependent manner.
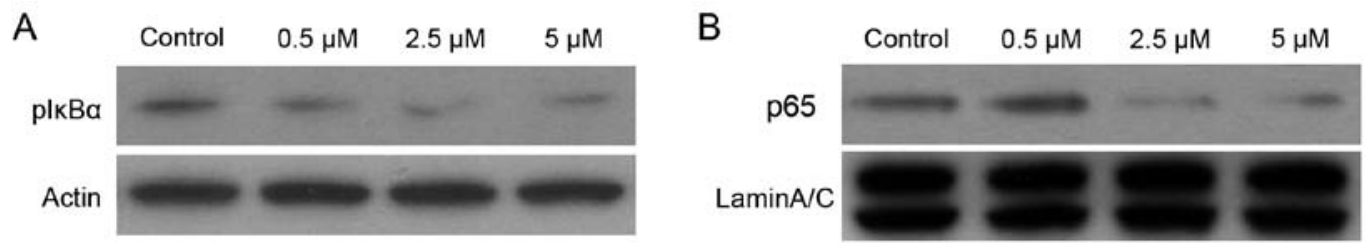

Figure 2. Effect of BMS-345541 on cytoplasmic level of pIkB and nuclear level of NF-kB/p65 in human prostate cancer PC-3 cells. (A) BMS-345541 dosedependently inhibited the phosphorylation of IкB $\alpha$ as detected by western blotting. Cells treated with BMS-345541 for $12 \mathrm{~h}$ were used for preparation of cytoplasmic extracts. Actin served as the loading control. (B) BMS-345541 inhibited NF- $\mathrm{\kappa B} / \mathrm{p} 65$ as detected by immunoblotting. Cells treated with BMS-345541 for $12 \mathrm{~h}$ were used for preparation of nuclear extracts. LaminA/C served as the loading control.

potential therapeutic agent (13). Hereby, we first assessed the effects of BMS-345541 on cell viability in PC-3 and LNCaP prostate cancer cells, respectively. PC-3 $\left(1 \times 10^{3}\right)$ and LNCaP $\left(5 \times 10^{3}\right)$ cell lines were cultured in medium with BMS-345541 at $0,2.5,5,10,15,20$ and $25 \mu \mathrm{mol} / 1$ concentrations. We then measured cell viability at different time points (8-96 h). From the results of MTT assay, the inhibition rate of prostate cancer cells treated with BMS-345541 showed a dose-dependent and time-dependent increase (Fig. 1). level of $N F-\kappa B / p 65$ in PC-3 cells. BMS-345541 was identi- fied as a selective inhibitor of the catalytic subunits of IKK (IKK $\beta \mathrm{IC}_{50}=0.3$ micron, $\mathrm{IKK}_{\alpha} \mathrm{IC}_{50}=4$ micron). It bands to similar allosteric sites on IKK $\alpha$ and IKK $\beta$, which then affects the active sites of subunits differently (14). The IкB $\alpha$ is constitutively phosphorylated in PC-3 cells by IKK (15). To evaluate the effect of the IKK inhibitor BMS-345541 on phosphorylation of $\mathrm{I} \kappa \mathrm{B} \alpha$, we performed western blotting using cytoplasmic extracts from PC-3 cells treated with DMSO or BMS-345541 (final concentration, 0.5, 2.5 and $5 \mu \mathrm{M}$ ) in DMSO for $12 \mathrm{~h}$. As shown in Fig. 2, treatment of PC-3 cells with $0.5,2.5$ and $5 \mu \mathrm{M}$ doses of BMS-345541 for $12 \mathrm{~h}$ resulted in a significant decrease in $\mathrm{p}-\mathrm{I} \kappa \mathrm{B} \alpha$ level in a dose-dependent 
A

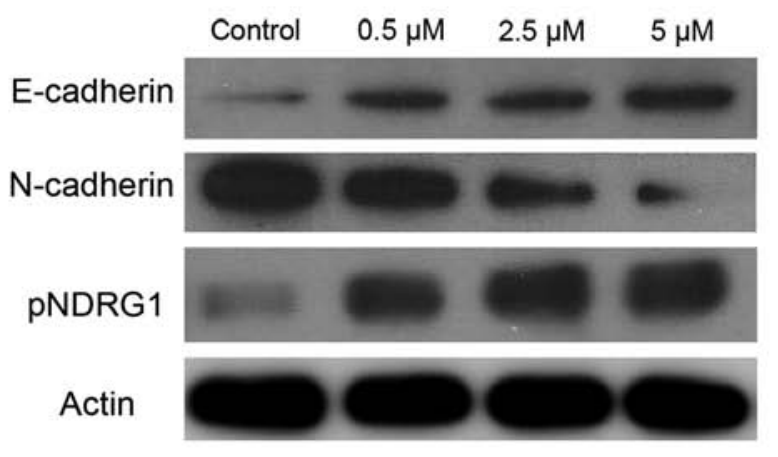

B Slug

Snail

Twist
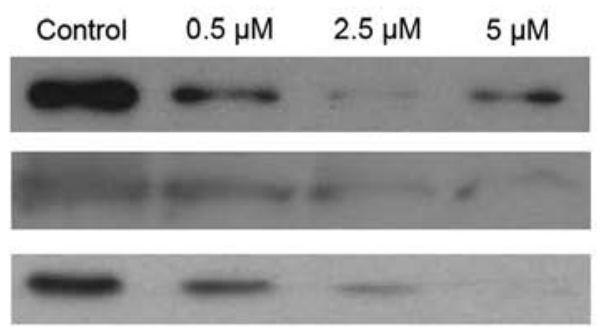

LaminA/C

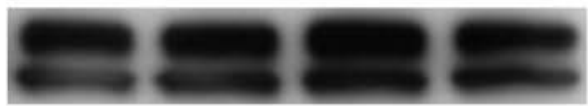

Figure 3. Effect of BMS-345541 on EMT in PC-3 cells. (A) BMS-345541 induced upregulation of the epithelial marker E-cadherin at protein level and downregulation of the N-cadherin, Snail, Slug and Twist proteins in a dose-dependent manner. Nevertheless, there was a significant increase in phosphorylated NDRG1 by blocking IKK in a dose-dependent manner.

\section{Control}

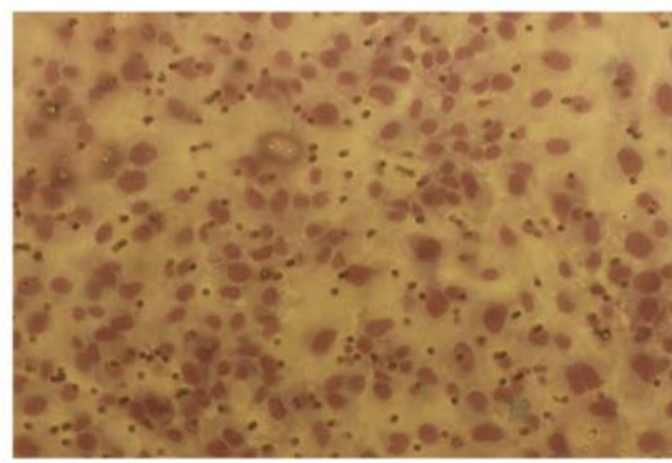

BMS-345541

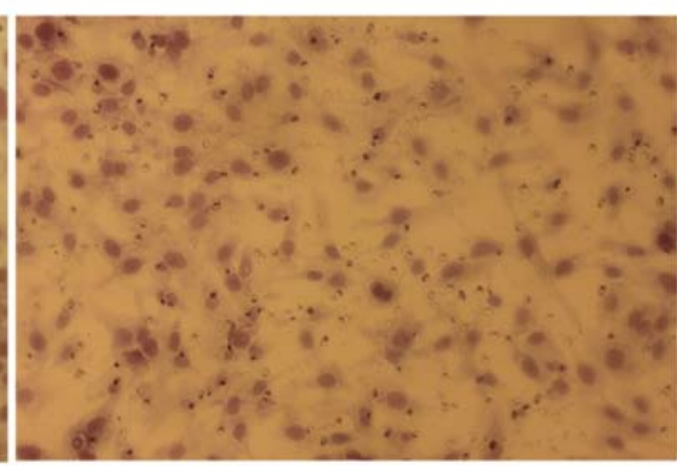

Figure 4. Effect of BMS-345541 on the invasiveness of human PC-3 cells. BMS-345541 significantly decreased the cell invasion through Matrigel-coated filters by $40 \%$ at $24 \mathrm{~h}$.

manner. Compared with DMSO-treated control, the level of inhibition was $50 \%$ at $5 \mu \mathrm{M}$ doses for $12 \mathrm{~h}$.

In addition, p50/p65 dimer is considered to be the most important of NF- $\mathrm{KB}$ proteins, and nuclear translocation of p50/p65 is required for their transactivation potential (16) Western blot analysis of nuclear protein from PC-3 cells treated with BMS-345541 showed a dose-dependent inhibition of the NF- $\kappa$ B/p65 level (Fig. 2). Compared with DMSO-treated control, a $60 \%$ inhibition in $\mathrm{NF}-\kappa \mathrm{B} / \mathrm{p} 65$ protein expression in the nucleus was observed $10 \mu \mathrm{M}$ dose of BMS-345541 for $12 \mathrm{~h}$.

BMS-345541 reverses EMT in PCa cells. Accumulated evidence suggests that prostate cancer cells can activate the process of EMT, and epithelial cells undergo multiple biochemical changes including expression of mesenchymal biomarkers, induction of angiogenesis and resistance to apoptosis (17-19). To characterize the effect of IKK inhibitor on EMT, we used BMS-345541 with varying concentration in PC-3 cells. As shown in Fig. 3, BMS-345541 induced upregulation of the epithelial marker E-cadherin at protein level. Nevertheless, we observed downregulation of the N-cadherin, Snail, Slug and Twist proteins in a dose-dependent manner.

$\mathrm{N}$-myc downstream-regulated gene 1 (NDRG1) is a potent metastasis suppressor that has been demonstrated to inhibit the
TGF- $\beta$ induced EMT in prostate cancer cells (20). To elucidate the molecular role of NDRG1 in EMT and the IKK inhibitor effect on NDRG1, immunoblot analysis was used to measure the level of phosphorylation of NDRG1 in PC-3 treated by BMS-345541. There was a significant increase in phosphorylated NDRG1 by blocking IKK in a dose-dependent manner (Fig. 3).

BMS-345541 decreases invasion and metastasis of PC-3 cells in vitro. We investigated whether BMS-345541 has an impact on invasion and migration of PC-3 cells, which is usually associated with the propensity to metastasis. The invasion ability of PC-3 cells was assessed by transwell invasion assay, and BMS-345541 significantly decreased the cell invasion through matrigel-coated filters by $40 \%$ at 24 h (Fig. 4). We further examined the cell migration by wounding cells plated on the cell culture plates. The result of wound healing assay showed that PC-3 cells treated by BMS-345541 were unable to recolonize the denuded zone as fast as the control cells did at $48 \mathrm{~h}$ after removal (Fig. 5).

The above results demonstrate that IKK inhibitor exerts a control on the invasion and migration capacities of prostate cancer cells and suggests that, besides its effect on the cell proliferative rate, it could also contribute to both tumor aggressiveness and metastasis. 


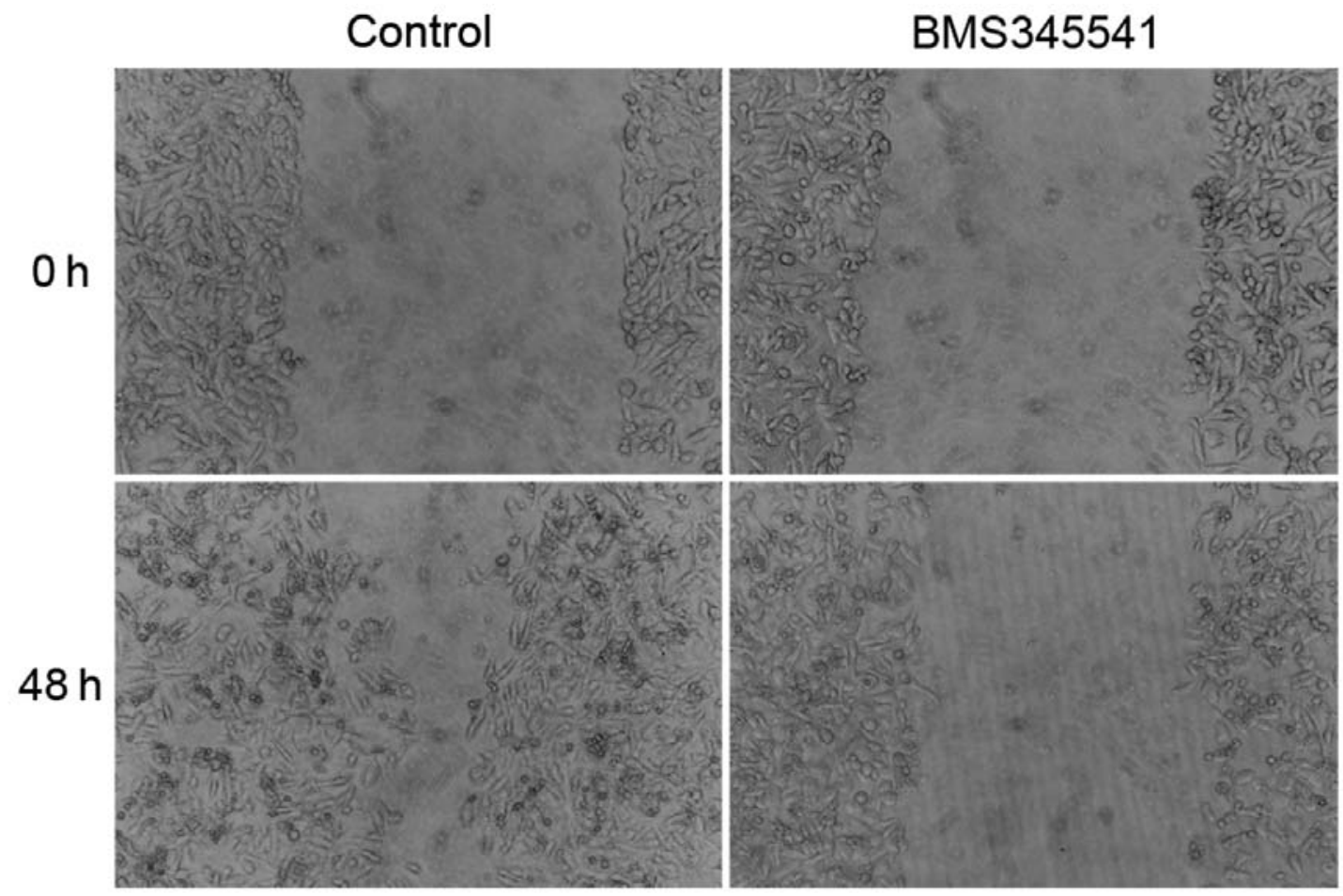

Figure 5. BMS-345541 inhibits migratory potential of human PC-3 cells. The result of wound healing assay showed PC-3 cells treated by BMS-345541 were unable to recolonize the denuded zone as fast as the control cells did at $48 \mathrm{~h}$ after removal.

\section{Control}

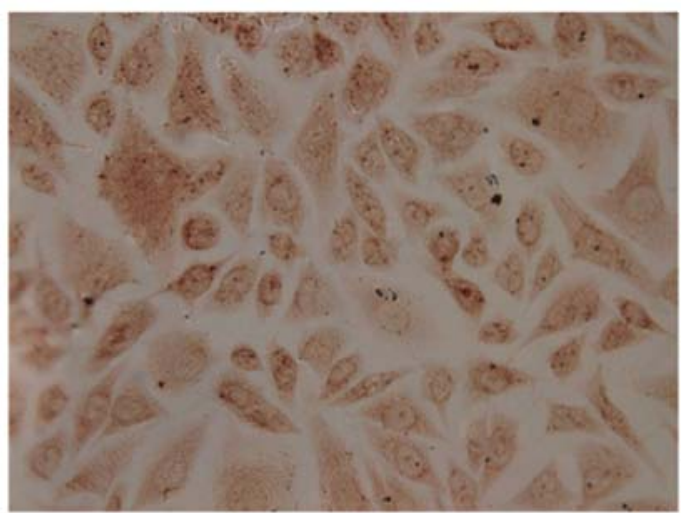

BMS-345541

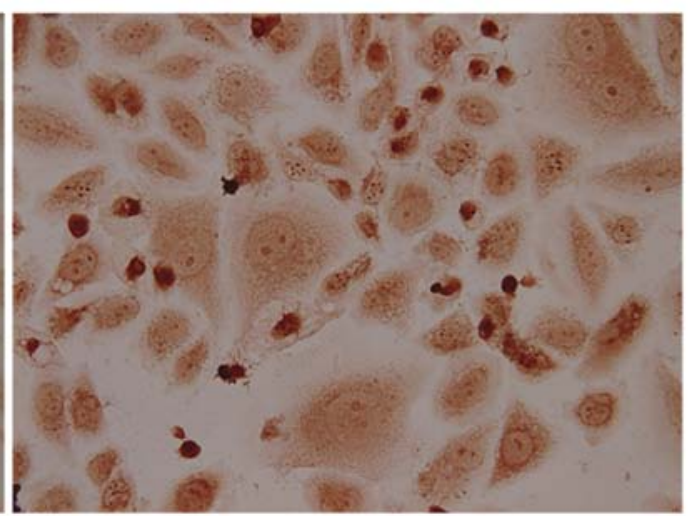

Figure 6. Effect of BMS-345541 on cell apoptosis in PCa cells examined by TUNEL assay. Apoptotic nuclei and fragmented DNA stained dark brown in treated cells, but not in the control cells.

BMS-345541 induces cell apoptosis of PC-3 cells. PC-3 cells after exposure to BMS-345541 for $72 \mathrm{~h}$ were examined by TUNEL assay. As shown in Fig. 6, apoptotic nuclei and fragmented DNA were stained dark brown in treated cells, but not in the control cells. The apoptotic index is significantly higher in the BMS-345541 treated cells than in the control (Table I).

To gain better understanding of the mechanism leading to cell death, we measured the combined effect of IKK inhibitor on the expression of Bcl-2 and Bax proteins. As shown in Fig. 7, the decreases in Bcl-2 expression were significantly greater in samples treated with BMS-345541 than those in control samples. Moreover, IKK inhibitor resulted in greater increases in Bax protein expression than untreated control.

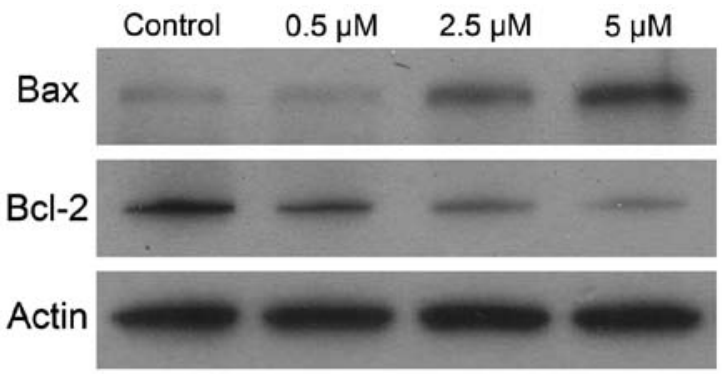

Figure 7. Effect of BMS-345541 on Bax and Bcl-2 expression in PC-3 cells. Expression of Bax and Bcl-2 was determined by western blotting. The decreases in Bcl-2 expression were significantly greater in samples treated with BMS-345541 than those in control samples. Moreover, IKK inhibitor resulted in greater increases in Bax protein expression than untreated control. 
Table I. Effect of BMS-345541 on apoptosis in prostate cancer PC-3 cells (TUNEL assay).

\begin{tabular}{lcc}
\hline Treatment & Apoptotic index $(\%)$ & P-value \\
\hline Control & $2.8 \pm 0.4$ & \\
BMS-345541 & $30.5 \pm 1.2$ & $<0.01$ \\
\hline
\end{tabular}

\section{Discussion}

Several lines of evidence suggest that $\mathrm{IKK} / \mathrm{NF}-\kappa \mathrm{B}$ pathway activation is a key event in the acquisition of invasive and metastatic capacities in prostate cancer (21). Furthermore, $\mathrm{NF}-\kappa \mathrm{B}$ expression is upregulated in patients with castration-resistant prostate cancer (CRPC) who progress more rapidly (13). The kinase subunits of IKK complex have previously been shown to be involved either directly or indirectly in the regulation of cellular proliferation (22). Hence, both IKK $\alpha$ and IKK $\beta$ are considered to be therapeutic targets for development of anticancer agents $(23,24)$. However, the precise mechanisms how it is achieved in prostate cancer are only partly understood. In this study, we characterized a highly selective IKK smallmolecule kinase inhibitor-BMS-345541, and demonstrated a key role of IKK in both EMT and apoptosis of prostate cancer. Unlike other reported IKK inhibitors, BMS-345541 was found to bind to an unidentified allosteric site of the catalytic subunits, and so behaves as an ATP-non-competitive inhibitor. The high selectivity of BMS-345541 for IKK $\alpha$ and IKK $\beta$ suggests that the allosteric site is unique to the IKKs, although it cannot be excluded that the site may also be present within other kinases not yet tested for selectivity (14). Especially, BMS-345541 is a potent and selective inhibitor of IKK $\alpha$ and IKK $\beta$. It displays 10 -fold greater selectivity towards IKK $\beta$ than IKK $\alpha$ with no activity towards $I K K \varepsilon$ or other protein kinases, even at concentrations as high as $100 \mu \mathrm{M}$.

In our study, we showed that BMS-345541 treatment results in a concentration-dependent suppression of prostate cancer cell survival in vitro. In addition, BMS-345541 could induce cell apoptosis and cause inhibition of tumor cell migration and invasion in PC-3 cells. Thus, we demonstrate the significant inhibitory effect on CRPC of IKK inhibitor. This phenomenon may involve several biologic properties such as EMT and programmed cell death existing in tumor cells. We found that BMS-345541 treatment resulted in inhibition of cytoplasmic $\mathrm{pI} \kappa \mathrm{B} \alpha$ and reduction of $\mathrm{NF}-\kappa \mathrm{B}$ p 65 nuclear translocation. Thus, significant blockade of $\mathrm{NF}-\kappa \mathrm{B}$ pathway was achieved by IKK inhibitor. Based on the complexity of signaling networks that regulate induction of EMT, and the plasticity of these transitions, it is important to focus on the most promising methods toward safe and effective reversal of EMT. IKK/ $\mathrm{NF}-\kappa \mathrm{B}$ appears to be a potential pathway in the regulation of EMT. Our results showed that IKK inhibitor reduced the critical EMT markers and transcription factors including $\mathrm{N}$-cadherin, Snail, and Slug in PC-3 cells. Nevertheless, the level of E-cadherin protein increased in a dose-dependent manner with BMS-345541 treatment.

$\mathrm{N}$-myc downregulated gene 1 (NDRG1) is a known metastasis suppressor in multiple cancers, being also involved in cell growth and differentiation, apoptosis, stress responses, angiogenesis and EMT $(25,26)$. However, the relationship of IKKs, EMT and NDRG1 is unclear. Here, we first confirmed the effects of IKK inhibitor on NDRG1 protein in prostate cancer cells. The results showed BMS-345541 induced upregulation of membrane pNDRG1 in a dose-dependent manner. It has been reported that NDRG1 modulated EMT through upregulation of the E-cadherin expression, but downregulation of the $\mathrm{N}$-cadherin, Snail, Slug, and Vimentin (27). We predict that there is a complex signaling network among IKK, NDRG1 and EMT which needs further studies in the future.

Several lines of evidence demonstrated that NF- $\kappa \mathrm{B}$ activation and NDRG1 downregulation can maintain tumor cell viability, and regulation targeting these factors is sufficient to induce apoptosis $(28,29)$. In our research, the TUNEL assay revealed IKK inhibitor regulated both NF- $\kappa$ B and NDRG1, and resulted in a dramatic induction of prostate cancer cell apoptosis. Molecules belonging to the B-cell lymphoma leukaemia-2 (Bcl-2)/Bax system play a crucial role in the regulation of the apoptotic process. In particular, Bcl-2 is an intracellular protein that inhibits apoptosis while Bax counteracts the anti-apoptotic function of Bcl-2 by binding to this molecule. Furthermore, we conformed that the cell apoptosis was mediated through Bcl-2 downregulation and Bax overexpression. The Bax/Bcl-2 ratio appears more important than the individual Bax or Bcl-2 level in determining cell apoptosis, and high $\mathrm{Bax} / \mathrm{Bcl}-2$ ratio leads to greater apoptotic activity.

In conclusion, the IKK inhibitor BMS-345541, significantly suppresses the growth, invasion, migration of prostate cancer cells in vitro, as well as induces cell apoptosis. The mechanism may involve in the blockade of IKK/NF- $\kappa$ B pathway and EMT, and NDRG1 plays an important role in this process. Our studies provide a rationale and molecular basis for IKK inhibitor in the clinical treatment of prostate cancer. IKK inhibitors have the potential as novel therapeutic agents to deal with the advanced prostate cancer in the future.

\section{Acknowledgements}

This study was supported by the Beijing Municipal Administration of Hospitals Incubating Program (code: PX2016050).

\section{References}

1. Bayne CE, Williams SB, Cooperberg MR, Gleave ME, Graefen M, Montorsi F, Novara G, Smaldone MC, Sooriakumaran P, Wiklund PN, et al: Treatment of the primary tumor in metastatic prostate cancer: Current concepts and future perspectives. Eur Urol: May 20,2015 (Epub ahead of print). S0302-2838(15)00378-4.

2. Miyake $\mathrm{H}$ and Fujisawa M: Prognostic prediction following radical prostatectomy for prostate cancer using conventional as well as molecular biological approaches. Int J Urol 20: 301-311, 2013.

3. Lei JH, Liu LR, Wei Q, Song TR, Yang L, Meng Y and Han P: Androgen-deprivation therapy alone versus combined with radiation therapy or chemotherapy for nonlocalized prostate cancer: A systematic review and meta-analysis. Asian J Androl 18: 102-107, 2016.

4. Nandana S and Chung LW: Prostate cancer progression and metastasis: Potential regulatory pathways for therapeutic targeting. Am J Clin Exp Urol 2: 92-101, 2014.

5. Clucas J and Valderrama F: ERM proteins in cancer progression. J Cell Sci 128: 1253, 2015.

6. Xu J, Lamouille S and Derynck R: TGF- $\beta$-induced epithelial to mesenchymal transition. Cell Res 19: 156-172, 2009. 
7. McConkey DJ, Choi W, Marquis L, Martin F, Williams MB Shah J, Svatek R, Das A, Adam L, Kamat A, et al: Role of epithelial-to-mesenchymal transition (EMT) in drug sensitivity and metastasis in bladder cancer. Cancer Metastasis Rev 28 335-344, 2009.

8. Min C, Eddy SF, Sherr DH and Sonenshein GE: NF-kappaB and epithelial to mesenchymal transition of cancer. J Cell Biochem 104: 733-744, 2008

9. Napetschnig $\mathbf{J}$ and $\mathrm{Wu} \mathrm{H}$ : Molecular basis of NF- $\mathrm{kB}$ signaling. Annu Rev Biophys 42: 443-468, 2013.

10. Kim SW, Schifano M, Oleksyn D, Jordan CT, Ryan D, Insel R, Zhao $\mathrm{J}$ and Chen L: Protein kinase C-associated kinase regulates $\mathrm{NF}-\kappa \mathrm{B}$ activation through inducing IKK activation. Int J Oncol 45: 1707-1714, 2014

11. Courtois $G$ and Israël $A$ : IKK regulation and human genetics. Curr Top Microbiol Immunol 349: 73-95, 2011.

12. Yang J, Amiri KI, Burke JR, Schmid JA and Richmond A: BMS-345541 targets inhibitor of kappaB kinase and induces apoptosis in melanoma: Involvement of nuclear factor kappaB and mitochondria pathways. Clin Cancer Res 12: 950-960, 2006.

13. Nguyen DP, Li J, Yadav SS and Tewari AK: Recent insights into $\mathrm{NF}-\kappa \mathrm{B}$ signalling pathways and the link between inflammation and prostate cancer. BJU Int 114: 168-176, 2014.

14. Burke JR, Pattoli MA, Gregor KR, Brassil PJ, MacMaster JF, McIntyre KW, Yang X, Iotzova VS, Clarke W, Strnad J, et al: BMS-345541 is a highly selective inhibitor of I kappa B kinase that binds at an allosteric site of the enzyme and blocks NF-kappa B-dependent transcription in mice. J Biol Chem 278: 1450-1456, 2003 .

15. Gasparian AV, Yao YJ, Kowalczyk D, Lyakh LA, Karseladze A, Slaga TJ and Budunova IV: The role of IKK in constitutive activation of NF-kappaB transcription factor in prostate carcinoma cells. J Cell Sci 115: 141-151, 2002.

16. Dyson HJ and Komives EA: Role of disorder in $\mathrm{I}_{\kappa} \mathrm{B}-\mathrm{NF} \kappa \mathrm{B}$ interaction. IUBMB Life 64: 499-505, 2012.

17. Luo Y, Cui X, Zhao J, Han Y, Li M, Lin Y, Jiang Y and Lan L: Cells susceptible to epithelial-mesenchymal transition are enriched in stem-like side population cells from prostate cancer. Oncol Rep 31: 874-884, 2014.

18. Behnsawy HM, Miyake H, Harada K and Fujisawa M: Expression patterns of epithelial-mesenchymal transition markers in localized prostate cancer: Significance in clinicopathological outcomes following radical prostatectomy. BJU Int 111: 30-37, 2013.

19. Thiery JP, Acloque H, Huang RYJ and Nieto MA: Epithelialmesenchymal transitions in development and disease. Cell 139: 871-890, 2009.
20. Chen Z, Zhang D, Yue F, Zheng M, Kovacevic Z and Richardson DR: The iron chelators Dp44mT and DFO inhibit TGF- $\beta$-induced epithelial-mesenchymal transition via up-regulation of N-Myc downstream-regulated gene 1 (NDRG1). J Biol Chem 287: 17016-17028, 2012.

21. Jain G, Voogdt C, Tobias A, Spindler KD, Möller P, Cronauer MV and Marienfeld RB: I $\kappa$ B kinases modulate the activity of the androgen receptor in prostate carcinoma cell lines. Neoplasia 14: 178-189, 2012.

22. Bradford JW and Baldwin AS: IKK/nuclear factor-kappaB and oncogenesis: Roles in tumor-initiating cells and in the tumor microenvironment. Adv Cancer Res 121: 125-145, 2014.

23. Tada Y, Kokabu S, Sugiyama G, Nakatomi C, Aoki K, Fukushima H, Osawa K, Sugamori Y, Ohya K, Okamoto M,

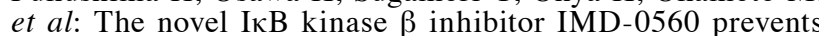
bone invasion by oral squamous cell carcinoma. Oncotarget 5: 12317-12330, 2014

24. Shi J, Chen J, Serradji N, Xu X, Zhou H, Ma Y, Sun Z, Jiang P, Du Y, Yang J, et al: PMS1077 sensitizes TNF- $\alpha$ induced apoptosis in human prostate cancer cells by blocking NF- $\mathrm{\kappa B}$ signaling pathway. PLoS One 8: e61132, 2013.

25. Fang BA, Kovačević Ž, Park KC, Kalinowski DS, Jansson PJ, Lane DJR, Sahni S and Richardson DR: Molecular functions of the iron-regulated metastasis suppressor, NDRG1, and its potential as a molecular target for cancer therapy. Biochim Biophys Acta 1845: 1-19, 2014.

26. Sánchez-Tilló E, Liu Y, de Barrios O, Siles L, Fanlo L, Cuatrecasas M, Darling DS, Dean DC, Castells A and Postigo A: EMT-activating transcription factors in cancer: Beyond EMT and tumor invasiveness. Cell Mol Life Sci 69: 3429-3456, 2012.

27. Lee JC, Chung LC, Chen YJ, Feng TH and Juang HH: N-myc downstream-regulated gene 1 downregulates cell proliferation, invasiveness, and tumorigenesis in human oral squamous cell carcinoma. Cancer Lett 355: 242-252, 2014.

28. McCall P, Bennett L, Ahmad I, Mackenzie LM, Forbes IWG, Leung HY, Sansom OJ, Orange C, Seywright M, Underwood MA, et al: NFKB signalling is upregulated in a subset of castrateresistant prostate cancer patients and correlates with disease progression. Br J Cancer 107: 1554-1563, 2012.

29. Kovacevic $Z$ and Richardson DR: The metastasis suppressor, Ndrg-1: A new ally in the fight against cancer. Carcinogenesis 27: 2355-2366, 2006. 